\title{
How to write a case report? Guidelines for Internists
}

\author{
Paola Gnerre, ${ }^{1}$ Micaela La Regina, ${ }^{2}$ Giorgio Ballardini, ${ }^{3}$ Giuseppe Chesi,${ }^{4}$ Paola Granata, ${ }^{5}$ Giovanni Scanelli, ${ }^{6}$ \\ Sirio Fiorino, ${ }^{7}$ Francesco Dentali, ${ }^{8}$ Roberto Nardi ${ }^{9}$ \\ ${ }^{1}$ Internal Medicine, San Paolo Hospital, Savona; ${ }^{2}$ Internal Medicine, POU del Levante Ligure, ASL 5, La Spezia; ${ }^{3}$ Internal \\ Medicine Unit II, Infermi Hospital, Rimini; ${ }^{4}$ Department of Internal Medicine, Sud Area AUSL Reggio Emilia; ${ }^{5}$ PAGEPress \\ Scientific Publications, Pavia; ${ }^{6}$ Internal Medicine Unit, AOU Ferrara, Arcispedale Sant'Anna, Ferrara; ${ }^{7}$ Internal Medicine, \\ Azienda USL di Bologna, Budrio (BO); ${ }^{8}$ Department of Clinical and Experimental Medicine, Insubria University, Varese; \\ ${ }^{9}$ Internal Medicine, Bologna, Italy
}

A case report is a detailed narrative of symptoms, signs, diagnosis, treatments and follow-up of one or several patients. Although, in evidence-based medicine, randomized clinical trials provide most of the scientific evidence, whereas case reports play in general a minor role, they represent an important part of medical practice. ${ }^{1}$ Case reports have significantly influenced the evolution of medicine, as can be seen in the literature in several examples of how they have contributed substantially to the advancement of science. The discovery of one of the most common forms of congenital thrombophilic abnormalities resulted from the description of a family with frequent episodes of thrombotic events. Likewise, a case report on the occurrence of hypoglycemia in a patient after injection of sulfur compounds led to uncover a new class of hypoglycemic drugs. ${ }^{2}$ They often report the first evidence of new therapies, but they are hardly ever sufficient to confirm their efficacy. They are frequently the first and sometimes major source of information about rare adverse events and the only one about rare cases. ${ }^{3}$ Case reports can also be regarded as a rich mine of hypotheses. All current knowledge about the infection from HIV clinical syndrome or septic shock resulted from the observation of individual cases. ${ }^{2}$ Therefore case reports have proven quite helpful in the identification of adverse and beneficial effects as well as unusual or novel manifestations of common or rare diseases. They can also be hypothesis-generating for fu-

Correspondence: Paola Gnerre, Ospedale San Paolo, via Genova 30,17100 Savona, Italy.

Tel.: +30.019 .8404082$

E-mail: pgnerre@yahoo.it

Key words: technical note, case reports, guidelines.

This work is licensed under a Creative Commons Attribution NonCommercial 3.0 License (CC BY-NC 3.0).

CCopyright P. Gnerre et al., 2014

Licensee PAGEPress, Italy

Italian Journal of Medicine 2014; 8:200-203

doi:10.4081/itjm.2014.535 ture clinical studies and useful sources of reference for personalizing treatments in clinical practice. ${ }^{4}$ For these reasons our Journal does not exclude the publication of case reports, however the Authors have to comply with a few rules for submission.

\section{Which cases do we want to publish?}

\section{Guidelines for publication of case reports}

According to the Journal policy, only cases with clinical valuable lessons and with clear proof of cause and effect will be published. Cases that present a diagnostic, ethical or management challenge or highlight aspects of mechanisms of injury, pharmacology and histopathology or are accompanied by a literature review of the topic presented are deemed of particular educational value. ${ }^{5}$ The narrative should include a discussion of the rationale for any conclusion and any take-home message. Information on the patient should be presented in the chronological order it has emerged in clinical practice. The evaluation will take into account the following aspects ${ }^{2}$ (Tables 1 and 2):

- Originality: unusual in the common clinical practice of the condition described.

- Quality of the presentation: compilation of case reports in accordance with the indications above.

- Correctness: adoption of commonly accepted diagnostic criteria for case definition and resolution of any diagnostic doubts.

- Sustainability: sustainability assessment of the conclusions based on the data presented.

- Usefulness/relevance: potential impact in current clinical practice.

\section{How to present case reports}

The text should not exceed 1500-1800 words, with a maximum of 1-2 tables and 3 figures and a final paragraph containing the key take-home messages. A maximum of 15 references are allowed. The cases with a literature review on the topic addressed may exceed the above limits. Case reports may not be sub- 
ject to review, whenever considered of little interest by the Editorial Board.

Table 3 shows the requested checklist for the submission of case reports to our Journal.

\section{Format for tables and figures}

If Tables are used, they should be double-spaced and numbered consecutively in the text.

If Figures are used, they should be submitted as .tiff or .jpg files (Power Point format is also accepted), with the following digital resolution:

i) color (saved as CMYK): minimum $300 \mathrm{dpi}$;

ii) black and white/grays: minimum $600 \mathrm{dpi}$;

iii) one column width $(7.5 \mathrm{~cm})$ or 2 column widths $(16 \mathrm{~cm})$.

A different caption for each figure must be pro- vided (typewritten) at the end of the manuscript and not included in the figure file.

Tables and figures should be attached separately from the text.

For further details, please also consult the PAGEPress Style Manual (par. 1.4. Tables and Figures, pp 12-16), downloadable from: http://www.pagepress. org/files/guidelines_authors.pdf

\section{Conclusions: beware of the main rules and tips}

Some journals do not publish case reports, whereas other journals publish only case reports. As hospital internists we believe that publishing clinical cases derived from the real world is important to our cultural development. Writing case reports is one of the best

Table 1. Criteria for case reports. ${ }^{5}$

Reminder of important clinical lesson

Findings that shed new light on the potential pathogenesis of a disease or an adverse effect

Learning from errors

Unusual presentation of more common disease/injury

Clinical complex problem-solving approach

Therapeutic challenges, controversies, or dilemmas

Report of new medical errors or pharmacological errors

Myth dispelled

Uniqueness of the case

Rare disease

New disease

Novel diagnostic procedure

Novel treatment (new drug/intervention; established drug/procedure in new situation)

Unusual association of disease/symptoms

Description of life-threatening adverse events

Opportunity for further research hypotheses

Review of a specific job description of a health care professional that improves patient care

Global health

Unexpected outcome

Table 2. Description of the case.

Is the case described adequately?

Is the case described briefly?

Is the case described clearly?

Are the results of investigations described adequately?

Are the results of less common laboratory tests accompanied by reference values? 
ways to get started in medical writing and to describe important scientific observations that may be missed or hard to notice in clinical trials. ${ }^{6}$ Case reports can retain the readers' interest and take less time compared with other kinds of publications. After describing the benefits that can potentially derive from the publication of case reports, we also need to recall some pos- sible limits to it. Major potential reason for rejection may be: lack of novelty (confirmation), inappropriateness of topic for the Journal, poor writing, plagiarism, redundant publication (as in the case of same data published in different journal, data on website and/or included in a previous review article).

Therefore, before submitting a case report, the au-

Table 3. Requested checklist for the submission of case reports to our Journal. ${ }^{5}$

Checklist to be fulfilled for the submission of case reports to our Journal

\begin{tabular}{|c|c|}
\hline Title & $\begin{array}{l}\text { The words case report or case study should be included in the title along with the key } \\
\text { element of the case (symptom, diagnosis, test, intervention) }\end{array}$ \\
\hline Key words & The key elements of this case in $2-5$ words \\
\hline Abstract & $\begin{array}{l}\text { - Introduction. What does this case add? } \\
\text { - Case presentation. Main symptoms of the patient, main clinical findings, main diagnoses } \\
\text { and interventions and main outcomes } \\
\text { - Conclusions. What are the main take-home lessons from the case report? }\end{array}$ \\
\hline Introduction & $\begin{array}{l}\text { Brief background summary of the case with references to the relevant medical literature: } \\
\text { - Describe the subject matter } \\
\text { - State the purpose of the case report } \\
\text { - Provide background information } \\
\text { - Provide pertinent definitions } \\
\text { - Describe the strategy of the literature review and provide search terms } \\
\text { - Justify the merit of the case report by using the literature review } \\
\text { - Introduce the patient case to the reader } \\
\text { Make the introduction brief and less than three paragraphs }\end{array}$ \\
\hline Patient information & $\begin{array}{l}\text { - Demographic information } \\
\text { - Main symptoms of the patient } \\
\text { - Medical, family and psychosocial history }\end{array}$ \\
\hline Clinical findings & Describe the relevant physical examination findings \\
\hline Timeline & $\begin{array}{l}\text { Report important dates and times in this case (in tables or figures): } \\
\text { - Check temporal relationship } \\
\text { - Check causal relationship } \\
\text { - Ensure that the patient case presentation provides enough details for the reader to } \\
\text { understand the case's validity }\end{array}$ \\
\hline Diagnostic assessment & $\begin{array}{l}\text { - Diagnostic challenges } \\
\text { - Diagnostic reasoning, including other diagnoses considered } \\
\text { - Prognostic characteristics where applicable } \\
\text { - Diagnostic methods }\end{array}$ \\
\hline Therapeutic intervention & Types of intervention (pharmacologic, surgical, preventive and self-care) \\
\hline Follow up and outcomes & $\begin{array}{l}\text { Summarize the clinical course of all follow-up visits including: } \\
\text { - Clinician and patient-assessed outcomes } \\
\text { - Important follow up test results } \\
\text { - Intervention compliance and tolerability } \\
\text { - Adverse and unanticipated events } \\
\text { Report the validity of the case report by applying a probability scale, such as the Naranjo } \\
\text { nomogram }\end{array}$ \\
\hline $\begin{array}{l}\text { Discussion } \\
\text { - Summarize the key features of the case report } \\
\text { - Justify the uniqueness of the case } \\
\text { - Draw recommendations and conclusions }\end{array}$ & $\begin{array}{l}\text { - Compare and contrast the strengths, nuances and limitations in the management of this case } \\
\text { - Explain or justify similarities and differences between the case report and the relevant } \\
\text { medical literature } \\
\text { - List the limitations of the case report } \\
\text { - The rationale for conclusions } \\
\text { - The main take-away lessons of this case report }\end{array}$ \\
\hline Patient perspective & The patient should share his or her perspective or experience whenever possible \\
\hline Informed consent & $\begin{array}{l}\text { Requested } \\
\text { - Obtain permission from the patient to use the patient's photographs } \\
\text { - Report the patient's events in chronological order }\end{array}$ \\
\hline
\end{tabular}


thors should read with particular attention the Journal Guidelines for Authors, available at: http://www. italjmed.org/ijm/about/submissions\#authorGuidelines

The authors should think about the Journal, its editors, and reasons for submission. They are requested to pay close attention to spelling, grammar, and punctuation, avoiding careless mistakes. References should be comprehensive and accurate.

\section{References}

1. Cohen H. How to write a patient case report. Am J Health Syst Pharm 2006;63:1888-92.

2. Mascella F, Ballardini G. Suggerimenti per la compi- lazione e la valutazione di abstracts di case reports o case series e per la loro presentazione ai congressi di FADOI Emilia Romagna. Ital J Med 2010;4:3-5.

3. Naranjo CA, Busto U, Sellers EM, et al. A method for estimating the probability of adverse drug reactions. Clin Pharmacol Ther 1981;30:239-45.

4. Guyatt GH, Meade MO, Jaeschke RZ, et al. Practioners of evidence based care. Not all clinicians need o appraise evidence from scratch but all need some skills. BMJ 2000;320:954-5.

5. Gagnier JJ, Kienle G, Altman DG, et al. The CARE guidelines: consensus-based clinical case reporting guideline development. J Med Case Rep 2013;7:223.

6. Leng S, Nallamothu BK, Saint S, et al. Simple and complex. N Engl J Med 2013;368:65-71. 